\title{
Study regarding the use of physical exercise in order to prevent school-age children from being overweight
}

\author{
Talaghir Laurentiu-Gabriel ${ }^{1 \mathrm{a}}$, Mîndrescu Veronica ${ }^{2}$ \\ ${ }^{1}$ University „Dunarea de Jos”,Domneasca Street, no. 46, 800008, Galati, Romania \\ ${ }^{2}$ Transilvania University, Bdul Eroilor, no. 29, 500036, Braşov, Romania
}

\begin{abstract}
In the present study, we aimed at applying a physical training program with simple exercises, focused on two aspects: on the one hand, we intended to lower body mass index and, on the other hand, to increase the level of physical fitness. We considered that both directions converge towards the formation of a healthy lifestyle.
\end{abstract}

Keywords: overweight, physical exercise, school-age children

\section{Introduction}

The most frequent cause of obesity is the lack of physical activity, the excessive intake of calories from food, even if there are also particular cases in which obesity may be hereditary or it may occur as a result of endocrine disorders or medicine ingestion.

Physical activity is, next to a balanced diet, the basis of a healthy life-style $[13,14]$ and is also very important for keeping healthy. In addition, physical activity is the perfect remedy for stress because it helps us relax and have a good night's sleep [1, 4, 7]. Specialists from different field of science which are related with a healthy life-style provide a lot o varieties type of efforts to prevent overweight $[2,3]$.

Obese people have a much greater calorie intake than their thinner counterparts because they must maintain a high body mass [5].

In 2010, [12] carried out a study in the USA that concluded that obesity is probably the result of the interaction between natural selection, which favours those with an accelerated metabolism, today's consumer society, in which everybody has easy access to cheap, energy-dense food, and the lower energy requirements of everyday life.

The food energy supply per inhabitant varies significantly between different regions and countries [14]. This supply has also changed depending on the period of time. From the beginning of the 1970s until the 1990s, the average calorie intake per person increased worldwide (with the exception of Eastern Europe). The greatest increase was recorded in

\footnotetext{
${ }^{a}$ Corresponding author: Gabriel.Talaghir@ugal.ro
} 
the United States, reaching 3654 calories in 1996 and 3754 calories in 2003. Calorie intake is closely connected to obesity.

This calorie intake increase mainly comes from carbohydrates. The primary sources of these carbohydrates are sweetened sodas and chips. The consumption of sweetened sodas is considered to have majorly contributed to the rising rates of obesity [15].

Because societies are increasingly dependent on meals which are rich in calories, because fast-food is more and more present in people's everyday life, the association between fast-food and obesity is becoming more and more alarming.

A sedentary lifestyle also plays an important role in obesity. There has been a major change worldwide because of the work that is physically less demanding and because, at present, at least $30 \%$ of the world population is taking too little physical exercise. The cause is mainly mechanised transportation, which is increasingly used, and the existence of technologies, which make work easier. The level of physical activity decreases in children because they walk less and they do not have as many physical education classes as they should [9].

Many children do not take physical exercises because they spend their time doing activities that do not involve movement like playing video games or watching TV. Technology is a great risk factor for children's physical activity. A healthy life-style means daily physical activity $[9,11]$.

The studies that focused on heredity models rather than on specific genes concluded that $80 \%$ of the children who had two obese parents also became obese, in contrast with less than $10 \%$ of the children who had two normal weight parents [6].

The thrifty gene hypothesis postulates that, because of the food shortage that existed during human evolution, people have a predisposition to obesity. Their ability to take advantage of the rare periods of abundance by storing energy as fat would be an asset in times of insufficient availability of food and people with higher fat reserves would be more likely to survive famine. Nevertheless, this tendency towards storing fat could be harmful in a society with stable sources of food [10].

Wellness is a complex concept, multifactorial and not very specific. Something, the lack of a healthy diet, sport practicing and a sum of other different factors (emotional and so on) could lead to sickness. Health issues occur and they affect our general metabolism, our osteoarticulatory / locomotion system, the endocrine and the nervous systems, and the bloodstream [16]. The present paper is the result of the equal contribution of both authors.

\section{Methods}

The research was carried out in Brăila, the county of Brăila, during school year 2015 2016, in the Pedagogical High school Perspessicius, on a number of 7 overweight subjects with ages ranging from 10 to 13 . The children participated in physical activities for a period of 7 months, twice a week. For each subject, the program was customized from the point of view of effort intensity, duration and exercise complexity.

The main aim of the research was to apply a physical training program, which followed two directions: on the one hand, the intention was to lower body mass index and, on the other hand, to increase the level of physical fitness. We considered both objectives to be an integral part of a healthy lifestyle.

In order to achieve the aim of the research, the subjects' body mass index and physical fitness were assessed by means of the following tests: push-ups, squats, pull-ups, hanging exercises and crunches.

The body mass index represents the ratio between weight and height. With the help of this indicator we may notice the correlation between the fat tissue and the total weight of fat. This indicator is considered to be the most used one in determining obesity. When the 
value of the BMI ranges from 19 to 24 , the person is considered to have an ideal weight. A value ranging from 25 to 30 means that the person is overweight, and over 30 , the person is considered to be obese.

The statistical analysis was performed with the help of the program SPSS 23 and we used the statistical method entitled The Pair Students' Test, where the significance threshold is $\mathrm{t}<.05$.

\section{Results and discussions}

Before the implementation of the physical training program, the subjects of the research were assessed in point of body mass index and physical training tests. We tested the students at the beginning of the program and after 7 months, at the end of the program. In order to be able to realize if the implementation of the physical training program was successful, we compared the obtained data by means of the statistical analysis described in table 1 .

Table 1. The comparative statistical analysis regarding the initial and final test results of the researched subjects

\begin{tabular}{|c|c|c|c|c|}
\hline \multirow{2}{*}{ TESTS } & \multicolumn{4}{|c|}{ Subjects (no $=7)$} \\
\cline { 2 - 5 } & $\overline{\mathrm{TI}}$ & $\mathrm{TF}$ & $\mathrm{t}$ & $\mathrm{p}$ \\
& $\overline{\mathrm{x}} \pm m$ & $\overline{\mathrm{X}} \pm m$ & & \\
\hline BMI & $28,14 \pm 0,78$ & $23,53 \pm 0,78$ & 12,15 & $<, 000$ \\
\hline Push-ups & $1,14 \pm 0,26$ & $8,00 \pm 1,30$ & 5,79 & $<, 001$ \\
\hline Squats & $9,57 \pm 0,99$ & $17,29 \pm 2,37$ & 7,45 & $<, 000$ \\
\hline Crunches & $9,57 \pm 0,99$ & $19,00 \pm 1,57$ & 5,73 & $<, 001$ \\
\hline Pull-ups & $0,71 \pm 0,18$ & $4,14 \pm 0,55$ & 6,49 & $<, 001$ \\
\hline Hanging exercises & $2,14 \pm 0,40$ & $8,86 \pm 0,63$ & 7,31 & $<, 000$ \\
\hline
\end{tabular}

The BMI indicated if, after implementing the physical activities, the subjects under research lost weight. In table 1 and figure 1, we may notice that there is a difference between the two tests. The average weight loss recorded in the final stage is of $50.42 \mathrm{~kg}$, that is to say an average of $8.71 \mathrm{~kg}$. less per person as compared to the initial stage.

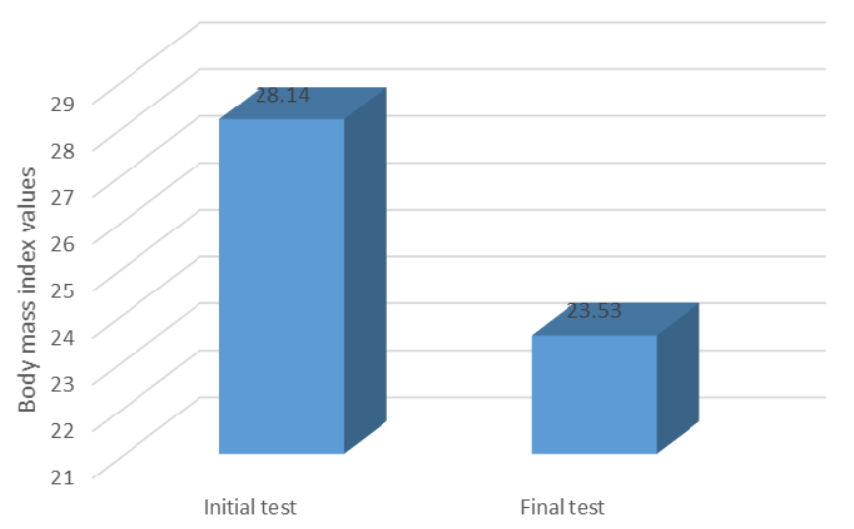

Fig, 1. The subjects' result evolution at the body mass index test

As a result of the performances obtained at the push-up test, we ascertain that the results obtained at the final test were better than those obtained at the initial test. 
This demonstrates the fact that physical activity improved the level of physical fitness of the researched subjects, the average reaching 6.86 repetitions, according to figure 2 .

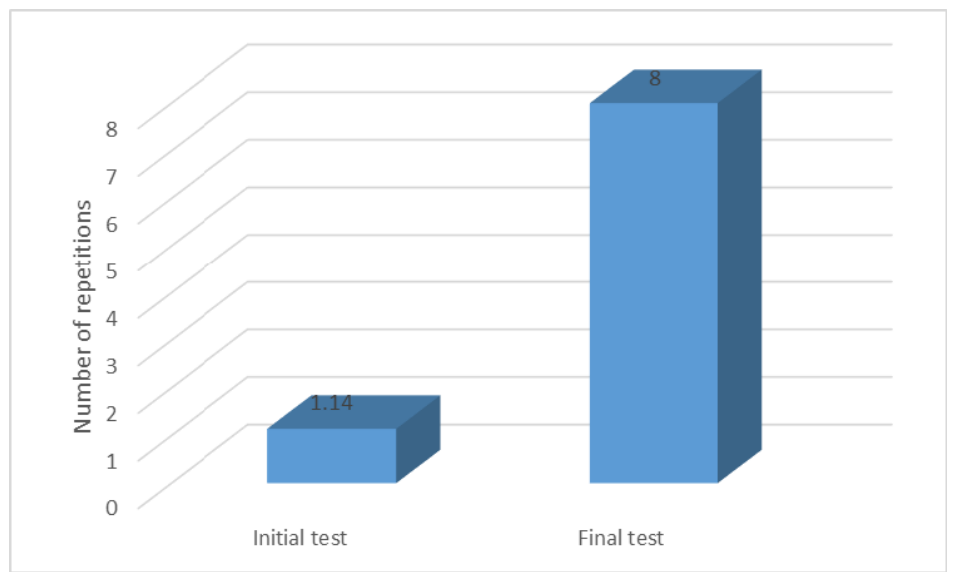

Fig. 2. The subjects' result evolution at the push-up test

Testing leg strength was achieved with the help of the squat test, where the subjects under research improved their performance at the final test, after implementing the physical activity program, with 7.72 repetitions, according to figure 3 . These performances are not random, this fact also being demonstrated by the statistical analysis where the significance threshold is $\mathrm{t}<.001$.

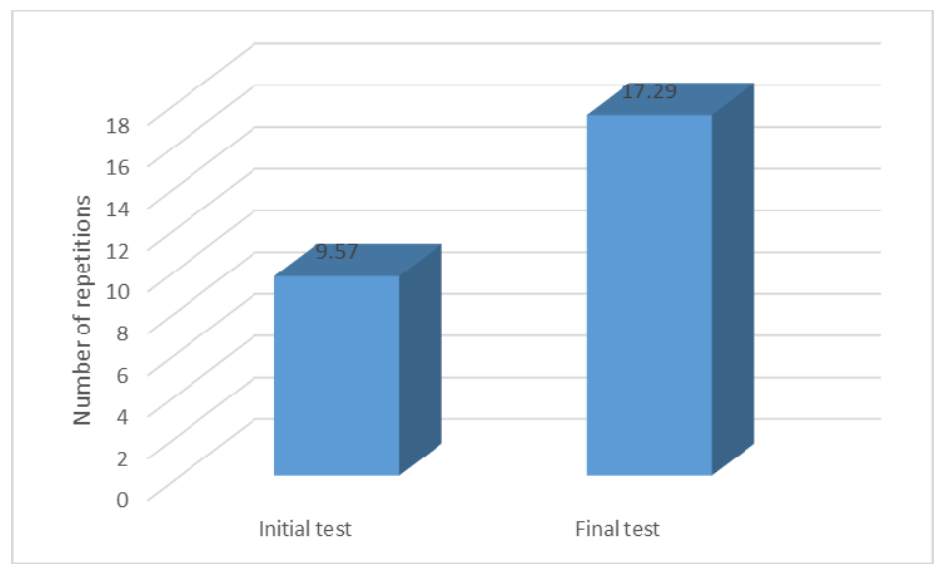

Fig. 3. The subjects' result evolution at the squat test

The values recorded at the crunch test indicate a low level of training at the initial test, which was improved at the final test with an average of 9.43 repetitions. The performance achieved at the final test is due to the physical training carried out by the researched subjects and is statistically supported by the results presented in table 1 and the performance averages presented in figure 4 . 


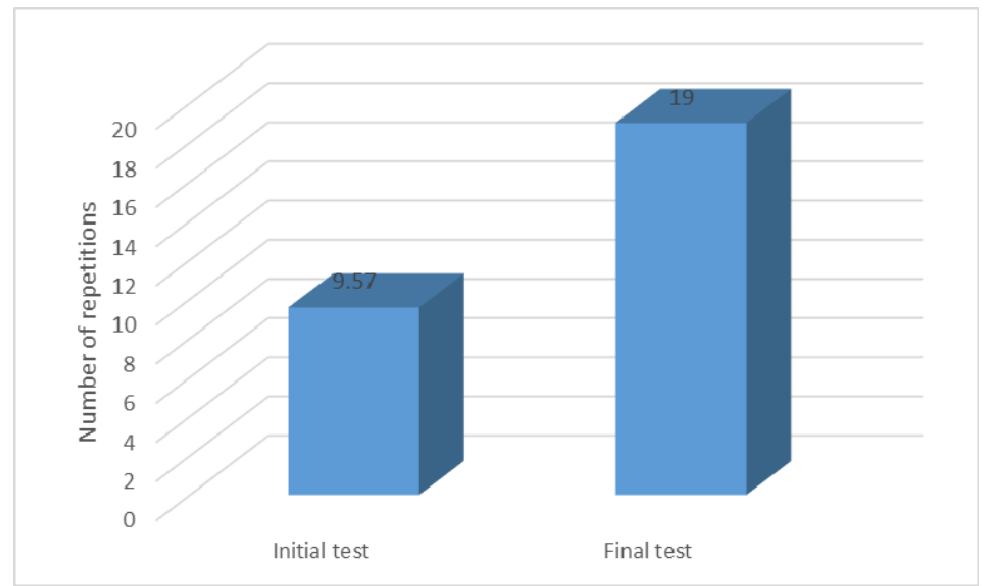

Fig. 4. The subjects' result evolution at the crunch test

At the arm strength test, significant progress was recorded, with an average of 1-3 repetitions, a good thing given the significant weight of the subjects. The progress is supported by the statistical analysis, where the significance threshold is of $t<.001$ and by the average of the results presented in figure 5.

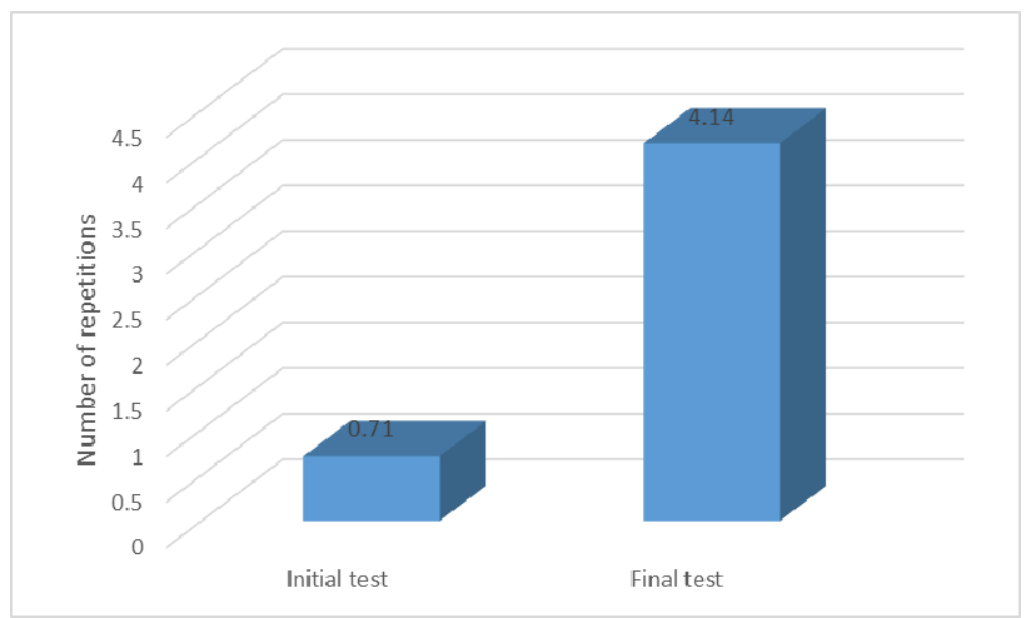

Fig. 5. The subjects' result evolution at the pull-up test

It is likely that this lack of significant progress is due to the lack, in our intervention, of a specific program dedicated to developing the muscle groups involved in this test or to the fact that certain fitness components weren't dealt with separately or, maybe, we should have focused on more weight loss.

In presenting the results obtained at this test, we checked muscle endurance and arm strength. As with previous tests, the subjects under research obtained an improvement of performance at the final test as compared to the initial test with an average of 6.72 repetitions. The improvement of the results confirms the fact that the physical training program applied to the subjects under research was well-applied and the content was well thought and organised. 


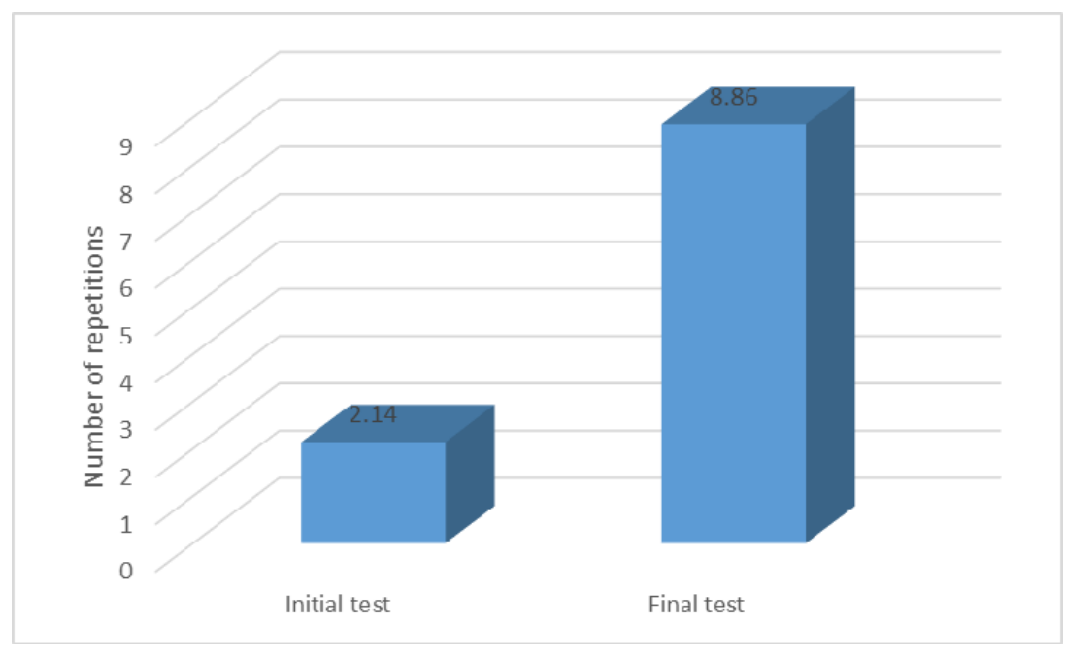

Fig. 6. The subjects' result evolution at the hanging exercises

The recorded progress is certain and obvious, being expressed in energy and strength, which, at the beginning of the training didn't exist. Even if, sometimes, the analysed tests didn't contain specific exercises, the proposed general physical training program was also positively transferred to the other body segments.

\section{Conclusions}

The main conclusion of our research was that physical exercises can be a great way to achieve an optimum body weight, which definitely represents a premise for good health.

At the same time, the pleasure of practising physical exercises will lead to better results obtained by the kids at their physical tests. Due to the fact that they increased their level of motricity, in the future, they would not avoid, to participate in physical activities, the foundation of a healthy lifestyle.

Another important aspect of the research is that, in order to fight childhood obesity, it is necessary both to see a nutritionist and to practise any kind of physical exercise.

We consider that kinetoterapy hasn't a significant effect in fighting obesity, especially in children. As long as they can perform voluntary specific motor activities, their practice represents the main element in burning the surplus of the daily intake of calories.

\section{References}

1. D. Bădău, A. Bădău, The influence of various types of water gymnastics upon the exercise capacity, International Journal of Science Culture and Sport (IntJSCS), Vol 3, No 4: Number: 14(94-102) (2015)

2. D. Bădău, A. Larion, A. Bădău, D. Alexandrescu, Experimental Study on Improving the Quality of Life through the Standardization of an Aerobics Program and of Effort Parameters Control using Pulse Tester, Mathematic Methods and Applied Computing (Volume II), Mathematics and Computers in Science and Engineering, A Series of Reference Books and Textbooks, WSEAS Press, pp. 610-615 (2009)

3. D. Bădău, G. Prebeg, D. Mitic, A. Bădău, Fitness index and VO2max of physical education students, Ovidius University Annals, Series Physical Education and Sport/Science, Movement and Health 15.2 S1: 246-252 (2015) 
4. E. Mcauley, S. Elavsky, GJ. Jerome, JF Konopack, DX. Marquez, Physical activityrelated wellbeing in older adults: Social cognitive influences. Psychology and Aging, 20, 295-302 (2005)

5. F. Raymond, Niciodată nu vei mai fi obez, All Publishing house, Bucureşti, (2007)

6. G. Kolata, Rethinking thin: The new science of weight loss - and the myths and realities of dieting. Picador, (2007)

7. G. Ninot, D. Delignieres, M. Fortes, L'évaluation de l'estime de soi dans le domaine corporel. STAPS, 53, 35-48, (2000)

8. J. Salmon, A. Timperio. "Prevalence, trends and environmental influences on child and youth physical activity". Med Sport Sci. Medicine and Sport Science, (2007)

9. Kr. Fox, The effects of exercise on selfperceptions and self-esteem. In: Physical Activity and Psychological Well-Being. Biddle J, Fox Kr, boutcher Sh (eds). Routledge, London and New York, b: 88-117, (2000)

10. M. V. Chakravarthy, F. W. Booth, Eating, exercise, and thrifty genotypes: Connecting the dots toward an evolutionary understanding of modern chronic diseases". J. Appl. Physiol. 96(1), 3-10, (2004)

11. R. Valois, HE. Zulling, JW. Drane, Physical activity behaviors and perceived life satisfaction among public high school adolescents. Journal of School Health, 74, 59$65,(2004)$

12. S. W. Keith, DT. Redden, KPT. Katzmarzy, A Plan for Measuring Progress, Institute of Medicine Evaluating Obesity Prevention Efforts, The National Academies Press, Washington DC, USA, (2013)

13. T. M. Iconomescu, M. Ciapa, L.G. Talaghir, G. Badicu, Survey regarding the importance of education for health trough physical education, The Annals of „Dunarea de Jos" University of Galati, Fascilce XV, Physical Education and Sport Management, no. 2, 62 (2013)

14. T. M. Iconomescu, M. Ciapa, L. G. Talaghir, V. Popescu, , Survey regarding the importance of sports to maintain a state of health good, The Annals of „Dunarea de Jos" University of Galati, Fascilce XV, Physical Education and Sport Management, 2, 67 (2013)

15. V. S. Malik, M. B. Schulze, F. B. Hu, Intake of sugar-sweetened beverages and weight gain: a systematic review. Am. J. Clin. Nutr., (2006)

16. Y. Netz, Mj Wu, B. J. Becker, G. Tenenbaum, Physical activity and psychological wellbeing in advanced age: a meta-analysis of intervention studies. Psychol Aging, 20, 272-284 (2005) 